\title{
Development of Wernicke's encephalopathy long after subtotal stomach-preserving pancreatoduodenectomy: a case report
}

\author{
Chikanori Tsutsumi ${ }^{1}$, Toshiya Abe ${ }^{1 *} \mathbb{B}$, Tomohiko Shinkawa ${ }^{1}$, Hideyuki Watanabe ${ }^{2}$, Kazuyoshi Nishihara ${ }^{1}$ \\ and Toru Nakano'
}

\begin{abstract}
Background: Wernicke's encephalopathy (WE) is an acute neuropsychiatric disorder resulting from thiamine (vitamin $B_{1}$ ) deficiency, frequently associated with chronic alcoholism and total parenteral nutrition without thiamine. However, only a few reports have focused on the relationship between WE and subtotal stomach-preserving pancreatoduodenectomy (SSPPD).

Case presentation: A 71-year-old woman underwent SSPPD for an adenocarcinoma of the ampulla of Vater. Although there had been no evidence of recurrence, the patient was treated with antibiotics for cholangitis at 12 and 31 months, respectively, post-surgery. Thereafter, the patient presented with vomiting and disorientation 33 months after surgery. Although she was admitted and underwent closer inspection by a neurologist and a psychiatrist, the exact cause of these syndromes remained unknown. The psychiatrist measured thiamine concentration to examine the cause of disorientation. After 6 days, her level of consciousness worsened. Magnetic resonance imaging of the head showed symmetrically multiple abnormal hyperintense signals on fluid-attenuated inversion-recovery and diffusion weighted image, compatible with WE. An administration of intravenous thiamine was immediately initiated. After 8 days of the measurement of the thiamine level, the patient's serum thiamine level was found to be $6 \mu \mathrm{g} / \mathrm{mL}$ (reference range, $24-66 \mu \mathrm{g} / \mathrm{mL}$ ). Accordingly, the patient was diagnosed with WE. Shortly after starting the treatment, blood thiamine value reached above normal range with significant improvement of her confusional state. However, short-term memory and ataxia remained.
\end{abstract}

Conclusions: Development of WE after SSPPD is uncommon. However, to prevent an after-effect, the possibility of development of WE after SSPPD should be recognized.

Keywords: Wernicke's encephalopathy, Subtotal stomach-preserving pancreatoduodenectomy, Thiamine

\section{Background}

Wernicke's encephalopathy (WE) is an acute neuropsychiatric disorder resulting from thiamine (vitamin $\mathrm{B}_{1}$ ) deficiency, leading to significant morbidity and mortality. It is characterized by a typical triad of mental status changes, nystagmus, and ataxia [1]. WE is frequently associated with chronic alcoholism and total parenteral nutrition without thiamine [2]. However, the relationship of WE with subtotal stomach-preserving pancreatoduodenectomy (SSPPD) has not been widely documented. We report an extremely rare case of WE developing 3 years after SSPPD.

\section{Case presentation}

*Correspondence: t-abe@surg1.med.kyushu-u.ac.jp

${ }^{1}$ Department of Surgery, Kitakyushu Municipal Medical Center, 2-1-1

Bashaku, Kokurakita-Ku, Kitakyushu 802-0077, Japan

Full list of author information is available at the end of the article
A 71-year-old woman underwent SSPPD for an adenocarcinoma of the ampulla of Vater, classified as stage IIB (pT1bN1M0) according to the 8th edition of the Union 
For International Cancer Control Tumor-Node-Metastasis classification. She experienced postoperative pancreatic fistula (PF) (Clavien-Dindo grade IIIa) [3], treated with drainage and antibiotics, and was discharged on day 21 , postoperatively. At that time, laboratory data demonstrated that albumin and lymphocyte were $4.0 \mathrm{~g} / \mathrm{dL}$ and $2050 / \mu \mathrm{L}$, respectively, not suggesting malnutrition. After that, she had less oral intake than preoperative intake in addition to fasting for a month in total due to recurrent cholangitis. An adjuvant chemotherapy including gemcitabine and cisplatin were administered for 6 months. Post-chemotherapy, she was on regular follow-up every 6 months, without evidence of recurrence. She was treated twice with antibiotics for cholangitis at 12 and 31 months, respectively, post-surgery. She had lost $8 \mathrm{~kg}$ compared to preoperative body weight at the first cholangitis, whereas hypoalbuminemia $(3.0 \mathrm{~g} / \mathrm{dL})$ and lymphopenia $(820 / \mu \mathrm{L})$ were present at the second cholangitis. She presented with vomiting 33 months after surgery. Additionally, her family complained of her disorientation. She was non-alcoholic, and had been able to eat until just before the onset of the symptom, except for the period of PF and cholangitis. On neurological examination, no specific findings were noted, including mental status despite her family complaint. She had not gained weight, since the onset of cholangitis. Laboratory data revealed hyponatremia $(133 \mathrm{mEq} / \mathrm{L})$, hypoalbuminemia $(3.2 \mathrm{~g} / \mathrm{dL})$, and lymphopenia $(810 / \mu \mathrm{L})$, suggesting mild malnutrition. However, computed tomography $(\mathrm{CT})$ and magnetic resonance imaging (MRI) of the head confirmed no specific findings. Although a neurologist and a psychiatrist examined closely, the exact cause of these syndromes remained unknown. The psychiatrist measured thiamine concentration to examine the cause of disorientation, whereas the laboratory measurement required 6-8 days. Thus, she underwent the treatment for hyponatremia until the results of thiamine value came. After 6 days, her level of consciousness worsened (Glasgow Coma Scale score, 3/15) [4]. Her comatose state made it difficult to evaluate other neurological findings. MRI of the head showed symmetrically abnormal hyperintense signal on fluid-attenuated inversion-recovery (FLAIR) and diffusion weighted image (DWI) in the frontal horn of lateral ventricle, the medial thalami bordering the third ventricle, the mammillary bodies, the periaqueductal region of the midbrain, and the bottom of the 4th ventricle (Fig. 1). As the MRI findings suggested WE, administration of thiamine (150 mg daily, intravenously) was immediately initiated. After 2 days, her serum thiamine level was $6 \mu \mathrm{g} /$ $\mathrm{mL}$ (reference range, 24-66 $\mu \mathrm{g} / \mathrm{mL}$ ). Accordingly, she was diagnosed with WE. Shortly after initiation of the treatment, blood thiamine value reached $246 \mu \mathrm{g} / \mathrm{mL}$, with significant improvement of her confusional state. After a
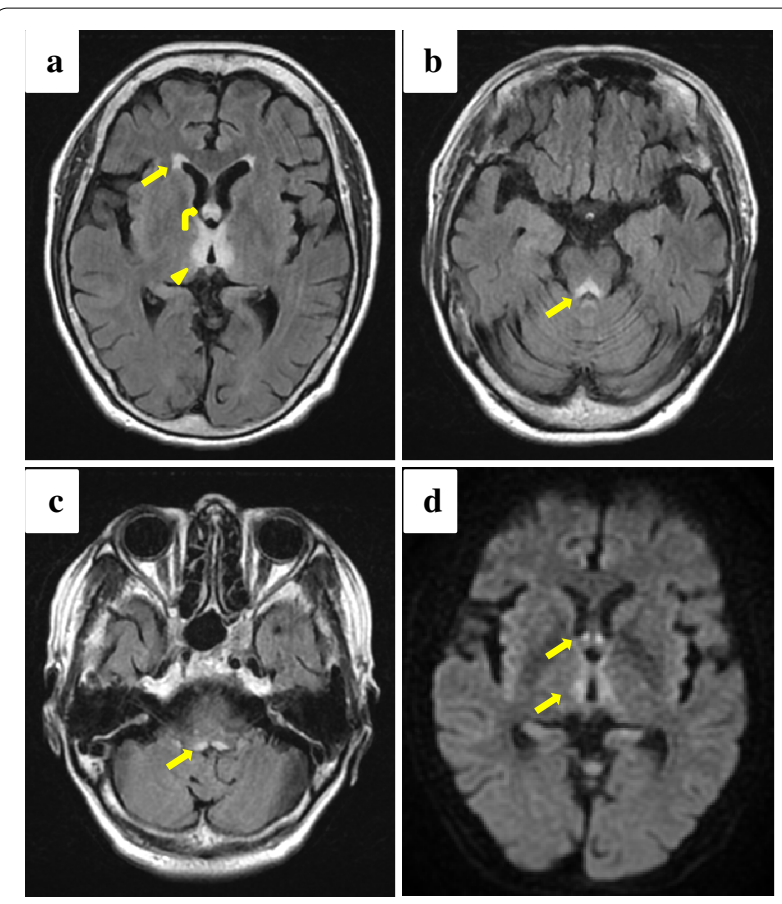

Fig. 1 a-d Contrast-enhanced MRI of the head showing symmetrically abnormal hyperintense signal on FLAIR in the frontal horn of lateral ventricle (a, arrow), the medial thalami bordering the third ventricle (a, arrow head), the mammillary bodies (a, curved arrow), the periaqueductal region of the midbrain ( $\mathbf{b}$, arrow), and the bottom of the 4 th ventricle (c, arrow). DWl imaging showing restricted diffusion corresponding to the FLAIR hyperintensities (d, arrows)

week of intravenous therapy, oral administration of thiamine $100 \mathrm{mg}$ daily was started. However, as short-term memory loss and ataxia remained, 3 weeks after starting the therapy, she was transferred to a rehabilitation hospital with continuation of thiamine administration. After 3 months, the memory impairment continued although walking with support was restored.

\section{Discussion}

WE is an acute neurological syndrome resulting from a deficiency in thiamine (vitamin $\mathrm{B}_{1}$ ), presenting with gait ataxia, nystagmus, and mental-status changes [1]. The main cause of thiamine deficiency is chronic alcohol abuse. The other notable causes include chronic dietary lack (unbalanced diet or parenteral nutrition without thiamine), poor absorption or low intake (pyloric obstruction, celiac disease, recurrent vomiting, or gravidic hyperemesis), excessive intake of carbohydrates in relation to the supply of thiamine, or a greater need for nutrition (growth, exercise, pregnancy, or infection) [2]. Thiamine is a water-soluble vitamin absorbed in the duodenum and breaks through the blood-brain 
barrier [5]. Additionally, it is taken up in the body via the thiamine transporter and its expression is higher in the duodenum and stomach [6]. Thus, the duodenum and stomach are important for oral absorption of thiamine. Recently, preoperative nutrition status in patients after pancreatoduodenectomy (PD) was reported to be significantly correlated with the prognosis [7]. However, the correlation with WE and PD remains to be clarified. PD is a surgical procedure to resect duodenum and a part of stomach, reducing oral absorption of thiamine post-surgery. Although improvements in the operative technique and perioperative care have reduced mortality [8], the rate of postoperative complications of $40 \%$ or above is still high [9]. The complications such as PF, cholangitis, and bile leakage, can lead to poor oral intake (POI). Body's store of thiamine is only sufficient for up to 18 days [1], and postoperative complications may further accelerate consumption of thiamine. The female in this case could not take anything orally for a certain period due to PF and recurrent cholangitis. In addition, laboratory data and loss of body weight suggested malnutrition at the time of onset. A search of the literature revealed only 11 patients developing WE after PD, including the present case [10-18] (Table 1). Almost all patients had aggravating factors such as POI, PF, and infections without tendency to develop WE in onset period. Shimomura et al. [19] stated that a late occurrence may be associated with a minor change in dietary habit precipitating a long-standing latent deficiency of thiamine. Therefore, POI due to PF and recurrent cholangitis might be related with late-onset WE in this case. In the present case, the development of WE may be explained by several causes, namely, the reduced duodenal and gastric mucosa useful for thiamine absorption, POI and increased requirement of thiamine secondary to PF and cholangitis, and minor change in dietary habit including decreased oral intake after SSPPD. Based on these findings, postoperative complications such POI, PF, and cholangitis after PD may be the risk factors for development of WE, in addition to thiamine malabsorption. Therefore, a combination of several factors may cause the development of WE after PD, although many cases who underwent PD did not develop WE.

The extent of gastrectomy is one-third in PD, whereas the stomach is largely preserved in SSPPD. Previous studies have reported most of the gastrointestinal surgeries such as gastrectomy and gastric bypass surgery as risk factors for WE $[20,21]$. Furthermore, these studies demonstrated that there was no tendency in the timing of onset and most of surgical procedures were Rouxen-Y reconstruction or gastrojejunostomy. However, the reports focusing on the correlation with WE and SSPPD are scarce. In a literature search, there were only two cases of SSPPD, including the present case [17]. The development of WE after gastrointestinal surgeries and after PD had in common that food did not pass through the duodenum. Accordingly, WE may develop after SSPPD.

Early diagnosis of WE may prevent the transition to Korsakoff's syndrome (KS) [1]. However, the typical classic triad is present in only $20 \%$ of patients with WE [22] and a substantial proportion of WE patients are undiagnosed or misdiagnosed. The literature search [10-18] (Table 1) revealed that $30 \%$ of the cases had three typical

Table 1 Preveous reports of WE patients underwent PD

\begin{tabular}{|c|c|c|c|c|c|c|c|c|}
\hline No & Author & Year & Age & Sex & Main complain & Operation (diagnosis) & Time to WE & Aggravaiting factor \\
\hline 1 & Tsujino [10] & 2007 & 68 & M & $\begin{array}{l}\text { Pedel edema, foot numb- } \\
\text { ness, ataxia }\end{array}$ & PD (AoV cancer) & 8 years & Loop diuretic \\
\hline 2 & Karayiannakis [11] & 2011 & 52 & $M$ & Disorientation, ataxia & PD (pancreatic cancer) & 1.2 years & Alcohol abuse, POI \\
\hline 3 & Onieva-Gonzanlez [12] & 2011 & 27 & M & $\begin{array}{l}\text { Disorientation, nystagmus, } \\
\text { ataxia }\end{array}$ & $\begin{array}{l}\text { PD (Duodenal ulcer bleed- } \\
\text { ing) }\end{array}$ & Several days & Peumonia, septic shock, POI \\
\hline 4 & Kilinc [13] & 2015 & 38 & $\mathrm{~F}$ & Nystagmus, ataxia & PD (pancreatic cancer) & 2 weeks & Obustraction, $\mathrm{POI}$ \\
\hline 5 & AbdekRazek [14] & 2018 & 54 & M & $\begin{array}{l}\text { Disorientation, nystagmus, } \\
\text { ataxia }\end{array}$ & PD (pancreatic cancer) & 5 years & $\mathrm{POI}$ \\
\hline 6 & Ji Su Kim [15] & 2018 & 65 & M & $\begin{array}{l}\text { Disorientation, nystagmus, } \\
\text { ataxia }\end{array}$ & $\begin{array}{l}\text { Laparoscopic PPPD (AoV } \\
\text { cancer) }\end{array}$ & 7 weeks & Bleeding, DGE, PF, POI \\
\hline 7 & Sogabe [16] & 2018 & 56 & $M$ & $\begin{array}{l}\text { Pedal edema, disorienta- } \\
\text { tion, ataxia }\end{array}$ & PD (AoV cancer) & 5 years & Not specified \\
\hline 8 & Kanesada [17] & 2018 & 72 & $\mathrm{~F}$ & Pedal edema, ataxia & SSPPD (pancreatic cancer) & 4 years & $\mathrm{POI}$ \\
\hline 9 & Monden [18] & 2019 & 77 & $\mathrm{~F}$ & Disorientation, ataxia & PD (bile duct cancer) & 4 years & $\mathrm{PF}$ \\
\hline 10 & Present case & 2020 & 71 & $\mathrm{~F}$ & Disorientation & SSPPD (AoV cancer) & 3 years & PF, cholangitis, POI \\
\hline
\end{tabular}


symptoms. In this case, WE was not suspected despite her family complaining of disorientation. As MRI findings suggested WE, the disease was strongly suspected. Determination of thiamine concentrations in the blood is central to the diagnosis of WE. However, laboratory measurement of thiamine value requires 6-8 days. In addition, Weidauer et al. [23] demonstrated MRI with a sensitivity of $53 \%$ and a specificity of $93 \%$, thus making the diagnosis of WE difficult. In the present case, second MRI revealed the suspicious findings of WE. This could be explained by the fact that WE got worse. On the other hand, lactic acidosis in WE results from failure of oxygen utilization due to mitochondrial dysfunction as thiamine is essential for mitochondrial metabolism [24]. Monden et al. [18] reported blood gas analysis including lactic acidosis to be useful for diagnosing WE. In the present case, we did not measure lactic acidosis. Moreover, thiamine deficiency can cause beriberi. Edema, a symptom associated with beriberi, was observed in $30 \%$ of the cases in the literature search [10-18] (Table 1). Therefore, in patients who underwent PD presenting with any of its typical symptoms or signs of heart failure, WE should be suspected and lactic acidosis may be useful for diagnosis.

WE, if left untreated, can progress to coma and even death. Furthermore, insufficient treatment leads to irreversible brain damage which may lead to death, with a mortality rate of about $20 \%$, or to the chronic irreversible form of the encephalopathy in $85 \%$ of survivors [25]. However, there is no sufficient evidence to guide the clinician regarding the optimum dose, route, and duration of thiamine treatment. Although the therapy was initiated at the same time as WE was suspected, this patient was administrated thiamine $150 \mathrm{mg}$ daily as large doses are not allowed under the Japanese insurance system. Unfortunately, short-term memory and ataxia remained. On the other hand, the European Federation of Neurological Societies guidelines recommend non-alcoholic WE patients to be treated intravenously with $200 \mathrm{mg}$ thiamine thrice daily [26]. In this case, higher doses of thiamine may have prevented her after-effects. Further studies are needed to determine appropriate thiamine therapy for WE.

\section{Conclusions}

Here, we report an extremely rare case of WE that developed 3 years after SSPPD. To prevent an after-effect, possible development of WE after SSPPD must be recognized.

\section{Abbreviations}

WE: Wernicke's encephalopathy; SSPPD: Subtotal stomach-preserving pancreatoduodenectomy; PF: Pancreatic fistula; CT: Computed tomography; MRI: Magnetic resonance imaging; FLAIR: Fluid-attenuated inversion-recovery; DWI:
Diffusion weighted image; PD: Pancreatoduodenectomy; POI: Poor oral intake; KS: Korsakoff's syndrome.

\section{Acknowledgements}

We would like to thank Editage (https://www.editage.com) for English language editing

\section{Authors' contributions}

CT wrote the manuscript. TA supervised the writing of the manuscript. TS and $\mathrm{KN}$ performed the surgical procedure and managed the patient's perioperative course. TN gave the final approval of this manuscript. All authors read and approved the final manuscript.

\section{Funding}

None.

\section{Availability of data and materials}

Not applicable.

\section{Ethics approval and consent to participate}

Not applicable.

\section{Consent for publication}

Written informed consent was obtained from the patient for publication of this case report and any accompanying images.

\section{Competing interests}

The authors declare that they have no competing interests.

\section{Author details}

${ }^{1}$ Department of Surgery, Kitakyushu Municipal Medical Center, 2-1-1 Bashaku, Kokurakita-Ku, Kitakyushu 802-0077, Japan. ${ }^{2}$ Department of Radiology, Kitakyushu Municipal Medical Center, Kitakyushu, Japan.

Received: 14 August 2020 Accepted: 18 September 2020

Published online: 25 September 2020

\section{References}

1. Sechi G, Serra A. Wernicke encephalopathy. Lancet Neurol. 2007;6:442-55.

2. Thomson AD, Marshall EJ. The natural history and pathophysiology of Wernicke's encephalopathy and Korsakoff's psychosis. Alcohol. 2006;41:151-8.

3. Clavien PA, Barkun J, de Oliveira ML, Vauthey JN, Dindo D, Schulick RD, et al. The Clavien-Dindo classification of surgical complications: five-year experience. Ann Surg. 2009;250:187-96.

4. Teasdale G, Maas A, Lecky F, Manley G, Stocchetti N, Murray G. The Glasgow Coma Scale at 40 years: standing the test of time. Lancet Neurol. 2014;13:844-54.

5. Reuler JB, Girard DE, Cooney TG. Current Concepts. Wernicke's encephalopathy. N Engl J Med. 1985:312:1035-9.

6. Reidling JC, Subramanian VS, Dudeja PK, Said HM. Expression and promoter analysis of SLC19A2 in the human intestine. Biochim Biophys Acta Biomembr. 2002;1561:180-7.

7. Abe T, Nakata K, Kibe S, Mori Y, Miyasaka Y, Ohuchida K, et al. Prognostic value of preoperative nutritional and immunological factors in patients with pancreatic ductal adenocarcinoma. Ann Surg Oncol. 2018;25:3996-4003.

8. Cameron JL, He J. Two thousand consecutive pancreaticoduodenectomies. J Am Coll Surg. 2015;220:530-6.

9. Pędziwiatr M, Małczak P, Pisarska M, Major P, Wysocki M, Stefura T, et al. Minimally invasive versus open pancreatoduodenectomy — systematic review and meta-analysis. Langenbeck's Arch Surg. 2017;402:841-51.

10. Tsujino T, Nakao S, Wakabayashi K, Lee M, Kimura T, Yoshikawa H, et al. Loop diuretic precipitated beriberi in a patient after pancreaticoduodenectomy: a case report. Am J Med Sci. 2007;334:407-9.

11. Karayiannakis AJ, Souftas VD, Bolanaki H, Prassopoulos PSC. Wernicke encephalopathy after pancreaticoduodenectomy for pancreatic cancer. Pancreas. 2011:40:1157-9. 
12. Onieva-González FG, Blanco-Fernández G, Munuera-Romero L, MárquezRojas J, Robles-Marcos M, Solórzano-Peck G. Wernicke's encephalopathy after cephalic pancreaticoduodenectomy. Rev Esp Enfermedades Dig. 2011;103:594-6.

13. Kilinc O, Caferov K, Koytak PK, Gunal DI, Uluc K. Wernicke's encephalopathy in two different clinical settings: one after Whipple surgery and the other due to alcohol abuse. J Neuropsychiatry Clin Neurosci. 2015;27:71-2.

14. AbdelRazek M, Han C, Albrecht A, Elsadek L, Yadollahikhales G, Elsadek R. Wernicke's encephalopathy 5 years after a whipple procedure. Neurohospitalist. 2018;8:3-4.

15. Kim JS, Rho SY, Hwang HK, Lee WJ, Kang CM. A case of Wernicke's encephalopathy following complicated laparoscopic pylorus-preserving pancreaticoduodenectomy. Ann Hepato-Biliary-Pancreatic Surg. 2019;23:295-9.

16. Sogabe K, Kawata M, Kodaira M, Kato Y, Takigami M, Kuroda M, et al. A case of beriberi heart disease with Wernicke-Korsakoff syndrome occurring in five years after duodenum resection. Heart. 2018;50:656-60.

17. Kanesada G, Watanabe J, Mukai N, Kusakabe E, Nakagawa M, Nishi Y, et al. Wernicke's encephalopathy after pancreaticoduodenectomy. EMJ. 2017;36:175-8 (in Japanese).

18. Monden K, Sadamori H, Hioki M, Ohno S, Rikimaru M, Saneto H, et al. Wernicke's encephalopathy after pancreaticoduodenectomy: a case report. Case Rep Clin Nutr. 2019;8511:1-7.

19. Shimomura T, Mori E, Hirono N, Imamura T, Yamashita H. Development of Wernicke-Korsakoff syndrome after long intervals following gastrectomy. Arch Neurol. 1998;55:1242-5.

20. Shuster MH, Vázquez JA. Nutritional concerns related to Roux-en-Y gastric bypass: what every clinician needs to know. Crit Care Nurs Q 2005;28:227-60.
21. Tozzo P, Caenazzo L, Rodriguez D, Bolcato M. Delayed diagnosis of Wernicke encephalopathy with irreversible neural damage after subtotal gastrectomy for gastric cancer: a case of medical liability? Int J Surg Case Rep. 2017;30:76-80.

22. Harper CG, Giles M, Finlay-Jones R. Clinical signs in the Wernicke-Korsakoff complex: a retrospective analysis of 131 cases diagnosed at necropsy. J Neurol Neurosurg Psychiatry. 1986:49:341-5.

23. Weidauer $S$, Nichtweiss M, Lanfermann H, Zanella FE. Wernicke encephalopathy: MR findings and clinical presentation. Eur Radiol. 2003;13:1001-9.

24. Donnino MW, Vega J, Miller J, Walsh M. Myths and misconceptions of Wernicke's encephalopathy: what every emergency physician should know. Ann Emerg Med. 2007;50:715-21.

25. Thomson AD, Cook CCH, Touquet R, Henry JA. Erratum: The Royal College of Physicians report on alcohol: guidelines for managing Wernicke's encephalopathy in the accident and emergency department. Alcohol. 2003;38:291.

26. Galvin R, Bråthen G, Ivashynka A, Hillbom M, Tanasescu R, Leone MA. EFNS guidelines for diagnosis, therapy and prevention of Wernicke encephalopathy. Eur J Neurol. 2010;17:1408-18.

\section{Publisher's Note}

Springer Nature remains neutral with regard to jurisdictional claims in published maps and institutional affiliations.

\section{Submit your manuscript to a SpringerOpen ${ }^{\circ}$ journal and benefit from:}

- Convenient online submission

- Rigorous peer review

- Open access: articles freely available online

- High visibility within the field

- Retaining the copyright to your article

Submit your next manuscript at $\boldsymbol{\nabla}$ springeropen.com 